\title{
Modelo territorial y principio de cooperación
}

\author{
Jaime Rodríguez-Arana \\ Catedrático de Derecho Administrativo \\ Universidad de La Coruña
}

El modelo territorial definido por la Constitución de 1978 se asienta sobre los principios de unidad, autonomía, integración y solidaridad, tal y como se deduce de la letra del artículo 2.1 de nuestra Constitución. En este merco, como ha señalado el Tribunal Constitucional; el principio de cooperación, aunque no se encuentra expresamente recogido en nuestra Carta magna, es un criterio que está ínsito en el modelo constitucional. Como sabemos, así ocurre en los modelos de Estado compuesto, y así ha de acontecer en una de sus variantes como es el Estado autonómico español.

En la presente exposición, me parece de interés tratar sobre el modelo territorial y la cooperación, partiendo de los criterios y parámetros constitucionales y del ambiente que rodeó la elaboración de la Constitución. Si no se tiene presente el marco, el sustrato en que se desenvuelve el modelo, difícilmente comprenderemos su caracterización y su sentido, por más que en el presente esté cuestionado por una minoría que aspira a sustituir el orden constitucional aprobado por el pueblo como unidad, expresión moderna de la soberanía que recoge la Constitución, a través de la modificación de una Ley Orgánica como es un Estatuto de Autonomía.

Desde este punto de vista, conviene recordar que en la historia de un país hay hitos históricos que contribuyen a conformar los rasgos de la ciudadanía política de sus habitantes. Olvidarlos, desvirtuar su sentido, o convertirlos en un tópico inerte, afecta de manera inmediata a nuestra propia identidad de ciudadanos. Por eso no es ocioso, sino un saludable ejercicio cívico, que recordemos la centralidad que entre nosotros ocupa el 6 de diciembre de 1978. Ese día se abrió para España, para todos los españoles, un esperanzador panorama de libertad, de justicia, de igualdad y de pluralismo político. Recordar esta fecha es reconsiderar el valor de estos preciados bienes, lamentar su ausencia en tantos años de nuestra historia, rememorar el esfuerzo de su consecución y reafirmar nuestro compromiso de preservarlos y enriquecerlos. El éxito de nuestro proceso constitucional fue en realidad un cúmulo de aciertos en el que todos participaron.

El espíritu de consenso, necesario para aprobar unas reglas comunes para todos los españoles, se puso particularmente de manifiesto en la elaboración de nuestro Acuerdo Constitucional. Muchos de nosotros podemos recordar con admiración la capacidad política, la altura de miras y la generosidad que presidió todo el proceso de elaboración de nuestra Constitución de 1978. Una 
vez más se cumplió la máxima de DAHLMANN: «En todas las empresas humanas, si existe un acuerdo respecto a su fin, la posibilidad de realizarlas es cosa secundaria...». Hoy, gracias al tesón y al esfuerzo de aquellos españoles, la consolidación de las libertades y el compromiso con los derechos humanos son un inequívoca realidad entre nosotros.

Porque ¿cuál es la herencia entregada en aquel momento constituyente, cuál es el legado constitucional? Un amplio espacio de acuerdo, de consenso, de superación de posiciones encontradas, de búsqueda de soluciones, de tolerancia, de apertura a la realidad, de capacidad real para el diálogo que, hoy como ayer, siguen fundamentando nuestra convivencia democrática.

Este espíritu al que me refiero - de pacto, de acuerdo, de diálogo, de búsqueda de soluciones a los problemas reales- aparece cuando de verdad se piensa en los problemas de la gente, cuando detrás de las decisiones que hayan de adoptarse aparecen las necesidades, los anhelos y las aspiraciones legítimas de los ciudadanos. Por eso, cuando las personas son la referencia para la solución de los problemas, entonces se dan las condiciones que hicieron posible la Constitución de 1978: la mentalidad dialogante, la atención al contexto, el pensamiento compatible y reflexivo, la búsqueda continua de puntos de confluencia y la capacidad de conciliar y de escuchar a los demás. Y, lo que es más importante, la generosidad para superar las posiciones divergentes y la disposición para comenzar a trabajar juntos por la justicia, la libertad y la seguridad desde un marco de respeto a todas las ideas. Cuando se trabaja teniendo presente la magnitud de la empresa y desde la tolerancia, cobra especial relieve el proverbio portugués que reza «el valor crea vencedores, la concordia crea invencibles». Podremos disentir en no pocas de las cuestiones que nos afectan a diario. Pero habremos de permanecer unidos en la absoluta prioridad de los valores que nuestra Constitución proclama. Valores en los que, en el día de hoy, no parece que los principales partidos quieran coincidir, presos como están de perspectivas cortoplacistas y estrategias de poder que les impiden contemplar la realidad desde los postulados del pensamiento abierto, plural, dinámico y complementario.

Como es sabido, el tercer inciso del preámbulo de la Constitución plantea la cuestión de los derechos humanos y el reconocimiento de la identidad política y cultural de los pueblos de España, al señalar la necesidad de «proteger a todos los españoles y pueblos de España en el ejercicio de los derechos humanos, sus culturas, tradiciones, lenguas e instituciones». La pregunta surge inmediatamente, ¿estamos los españoles y nuestros pueblos protegidos frente a la aspiración, legítima por supuesto, pero notoriamente minoritaria en términos generales, de transformar el modelo territorial de forma unilateral?

Pues bien, este principio general expresado en el preámbulo se ve traducido, en el artículo 2 de Constitución, como ya hemos señalado, en el reconocimiento de la identidad política de los pueblos de España, al garantizar 
MODELO TERRITORIAL Y PRINCIPIO DE COOPERACIÓN

el derecho a la autonomía de las nacionalidades y regiones que integran la Nación española, así como la solidaridad entre todas ellas, lo que se ha concretado, tras más de veintisiete años de desarrollo constitucional, en un modelo de Estado que goza de una razonable consolidación y estabilidad, como lo prueba la cantidad y calidad de las competencias asumidas por las Comunidades Autónomas, a pesar del actual desafío que plantea el Estatut de Cataluña, de Illes Balears y de la Comunidad Valenciana. Y desde luego que, para muchos de nosotros, este respaldo jurídico-político a la realidad plural de España es uno de los principales aciertos de nuestra Constitución y un motor para nuestro progreso cultural y político.

Sin embargo no dejan de producirse, en torno a esta cuestión, recelos mutuos entre ciertos sectores, de una parte los de quienes aspiran a la afirmación nacional que de hecho rompe el marco constitucional, y de otra los de quienes consideran que la unidad de España debe poner coto a los excesos autonomistas. Ante estas tensiones, hoy bien reflejadas en nuestra realidad diaria, es necesario apelar al consenso como metodología para el desarrollo constitucional, particularmente en este punto - en lo referente al Título VIII- porque nos encontramos ante una cuestión que afecta esencialmente a la misma concepción del Estado. No se trata de elaborar un nuevo consenso, sino de establecer nuevos consensos sobre la base del consenso constitucional. Y la Constitución ha querido que el derecho al autogobierno se reconozca a la vez que la solidaridad entre todas las Autonomías. Es cierto que las Comunidades Autónomas, en cuanto que identidades colectivas con una personalidad propia manifiestan sus legítimas particularidades y singularidades. Los usos políticos han denominado a estas particularidades «hechos diferenciales», denominación adecuada precisamente en la medida en que existen elementos comunes.

Pues bien, la existencia de esas diferencias o singularidades - como se quieran llamar- promueve un enriquecimiento constante y dinámico de ese conjunto que se llama España, vertebrado como un Estado autonómico, y en el que la potenciación y desarrollo de las distintas partes, mejora el conjunto.

En este sentido, me parece atinada la explicación sobre España como la del conjunto y las partes, que hacía ORTEGA Y GASSET, no sólo por sus evidentes connotaciones históricas sino porque supone la llamada a otros criterios constitucionales como pueden ser la solidaridad y la cooperación. En este marco, España constituye un magnífico espacio de solidaridad y convivencia siempre desde la plena aceptación de las diferentes identidades que la integran, en un ejercicio activo de compromiso en el respeto a las diferencias. Por eso, la cooperación al bien de todos y común, parece el mejor bien posible para cada uno.

Ahora bien, si es preciso moderar los excesos diferencialistas, debe recordarse al mismo tiempo que donde hay unidad uniformante no hay cooperación, todo lo más habrá operatividad o capacidad operativa. La cooperación implica, necesita la diversidad, la pluralidad, la aportación diversa de los que 
cooperan y tienen un objetivo común. Además, no se trata de una solidaridad mercantilista, sino de una solidaridad en la que cada identidad se esfuerza para la mejora propia, la de los demás y la del conjunto, en la medida y la forma en que esto sea posible. Por eso hablamos de autonomía y de integración, en un equilibrio que conviene encontrar entre todos, para cada momento. En este sentido, la Constitución se nos presenta como un instrumento jurídico y político adecuado para la consecución de tan fecundo equilibrio, que tenemos que saber alcanzar y desarrollar inteligente y respetuosamente los unos con los otros.

Hay que observar, sin embargo, que buena parte de estos conflictos de entendimiento derivan de ciertas deficiencias - ampliamente reconocidasde nuestro modelo político, de nuestro desarrollo constitucional, que no han sido convenientemente solucionadas. En concreto, me estoy refiriendo a la necesidad de la reconversión del Senado en una auténtica Cámara de representación territorial, a tenor de lo dispuesto en el artículo 69 de la Carta Magna. Un Senado auténticamente territorial, por ejemplo como Cámara de primera lectura para todos los asuntos con trascendencia territorial traería consigo, por su propia lógica, un ambiente de mayor responsabilidad desde las perspectivas particulares en los asuntos generales, de todos, y consecuentemente un ambiente de mayor solidaridad y equidad. Por fin tendríamos una Cámara en la que estarían representadas proporcionalmente los Entes territoriales, una Cámara que haría posible la institucionalización de una nueva perspectiva autonómica: la multilateralidad, una nueva dimensión que, de seguro, simplificaría enormemente los problemas y aseguraría mayores cotas de solidaridad y equidad en el sistema, y sobre todo de transparencia, al hacer más patente el reflejo institucional de la realidad plural de España. Cierto que algunos planteamientos nacionalistas radicales se perfilan como el obstáculo más importante en la búsqueda de una solución a este problema institucional. Si de momento no pudiéramos resolverlo habremos de aprender a convivir con él. Nos lo exige el ejercicio de la convivencia constitucional.

Precisamente, en este marco de equilibrio que es necesario redifinir, se encuadra otro elemento del diseño territorial que parece llegado el momento de abordar para conferirle la posición y la dimensión que la Constitución le asigna. Me refiero, claro está, a los Entes locales, que deben disponer efectivamente de la autonomía que constitucionalmente les está garantizada. La libertad y la justicia no se producen en las grandes declaraciones ni en las estructuras jurídicas superiores, sino que se dan en los entornos personales de la existencia, o no se dan. Por eso, adecuar la posición institucional y competencial de los Entes locales a las exigencias constitucionales es, a mi juicio, una tarea inaplazable, si tenemos presentes los principios de proximidad y cercanía a la gente que deben guiar las actuaciones de la Administración. Y es urgente también, si queremos dotar a nuestro sistema político y cívico del equilibrio necesario en la distribución territorial del poder. 
MODELO TERRITORIAL Y PRINCIPIO DE COOPERACIÓN

Al abordar la cuestión de la articulación territorial de España, desde los presupuestos que denomino del pensamiento abierto, plural, dinámico y compatible o complementario, es preciso analizar la incidencia de esta metodología de trabajo sobre los contenidos del sistema.

En primer lugar, el sentido realista, exige un esfuerzo de aproximación a la realidad y de apreciarla en su complejidad. No es que tal aproximación resulte fácil, o que lo encontrado en ella sea indiscutible, pero sin entrar en la discusión de fondo sobre las posibilidades del conocimiento humano, digamos que es necesario ese esfuerzo de objetividad, que no puede ser afrontado sin una mentalidad abierta. La mentalidad abierta, la ausencia de dogmatismos, es necesaria no sólo para comprender la realidad, sino para comprender también que puede ser entendida por diversos sujetos de formas diversas, y que esas diversas aproximaciones forman también parte de la realidad. La complejidad de lo real y su dinamismo deben ser abordados con una actitud adecuada, que en ningún caso pretenda negarla, y que integre igualmente su complejidad, viendo como compatibles todos sus componentes, y su dinamismo.

La realidad plural de España es aceptada por todos prácticamente. Ni desde los esquemas más ultramontanos del unitarismo español deja de reconocerse, con fórmulas más o menos pintorescas, la realidad diversa de los pueblos y autonomías de España. Pero desde ese planteamiento, tal variedad se aprecia como un adorno, o un accidente, de la unidad esencial española, como una entidad superficial, casi folclórica, podríamos decir, que no haría en todo caso más que resaltar el esplendor de lo que tenemos en común, que sería lo verdaderamente importante. Cuántas veces, en cuántas ocasiones, hemos escuchado retóricas exaltaciones de las literaturas o de las lenguas llamadas regionales, pongamos por caso, como apéndices o curiosas peculiaridades de una realidad cultural española - de fundamento castellano- supuestamente sustantiva y a la que aquellas otras se considera subordinadas. Y además, ante esas identidades culturales que se ven como secundarias o subordinadas, se manifiestan a continuación suspicacias contumaces cuando de ellas se quiere hacer un uso normal en todos los ámbitos de la vida y la actividad pública.

Por eso, el acuerdo y mandato constitucional relativo a la defensa de la identidad cultural y política de los pueblos de España, o, por decirlo de un modo más amplio, la estructuración autonómica de España, me parece uno de los aciertos más importantes de nuestros constituyentes. Y también, por eso, porque responde a una realidad, y además a una realidad que juzgamos positiva, por cuanto realmente -no retóricamente- nos enriquece a todos, es por lo que desde el pensamiento compatible y dinámico no es posible una actitud que no sea de apoyo y potenciación para esas culturas, lejos de los que sienten nostalgia de un integrismo uniformante o de los que propugnan particularismos que consideramos excesivos. Así, por ejemplo, por muy conflictiva o problemática que pueda parecer a muchos la pluralidad cultural de España, en absoluto, desde el pensamiento compatible y dinámico, se puede 
mirar con nostalgia o como un proyecto de futuro una España culturalmente uniforme, monolinguie, por ejemplo, ya que esta aproximación sería una pérdida irreparable. Expresado positivamente, debo afirmar que no sólo deseo sino que apuesto por unas lenguas vasca, catalana, gallega o valenciana, pujantes y vigorosas y conformadoras del sentir de cada una de las comunidades que la hablan en el marco de un proyecto común abierto y de conjunto.

El pensamiento compatible y dinámico significa, entre otras cosas, la afirmación plural de la realidad española, incluso y sobre todo desde la identidad gallega, vasca, catalana, andaluza o cualquier otra de las que integran España. Constitucionalmente esto es, me parece, incontestable, pero es necesario hacer de la propuesta jurídica algo vivo y real. Es necesario reiterar que la afirmación de la identidad particular de las Comunidades de España, no tiene, ni mucho menos, que suponer la negación de la realidad integradora de España. Y también parece menester repetir, por lo tanto, que la afirmación de España no puede ser ocasión para menoscabo alguno de la identidad particular.

La obligación de las instancias públicas de preservar y promover la cultura de las nacionalidades y regiones no es una concesión graciosa del Estado, sino un reconocimiento constitucional, es decir, constitutivo de nuestro régimen democrático. Por tanto, los poderes públicos no deben ser indiferentes ante los hechos culturales diferenciales. Pero igualmente, la interpretación de esa obligación debe hacerse tomando en consideración un bien superior que a mi entender fundamenta la construcción constitucional de una España plural, que no es otro que el de la libertad. Sólo en una España de libertades cabe una España plural. Pero las libertades son ante todo libertades individuales, de cada uno. Cualquier otra libertad será una libertad formal, o abstracta. Por eso la promoción de la cultura particular no podemos interpretarla sino como la creación de condiciones favorables para que los ciudadanos, libremente, la desarrollen, nunca como una imposición, ni como un proceso de incapacitación para el uso libre de los medios que cada uno considere oportunos para su expresión.

La solidaridad es otro principio central en la interpretación de la realidad plural de España. Pienso que nadie está legitimado en España para hablar de deuda histórica, porque todos somos deudores de todos, de ahí la pertinencia de España como proyecto histórico de convivencia, que a todos enriquece. Pero hoy, la solidaridad real exige justamente de los más ricos el allegamiento de recursos para atender a las personas y territorios más deficientes en medios, servicios y posibilidades. Sin embargo este planteamiento no puede hacerse con la pretensión de establecer un régimen permanente de economías subsidiadas. La solidaridad es también una exigencia para el que podríamos considerar beneficiado de ella, pues en su virtud le es exigible un esfuerzo mayor para superar su situación de atraso, asumiendo, desde luego, las limitaciones de sus posibilidades reales.

Esta concepción de la realidad española no es nueva, podrá decirse. Efectivamente, nadie podría pretenderlo. Pero se trata de que la sociedad haga una 
MODELO TERRITORIAL Y PRINCIPIO DE COOPERACIÓN

asunción real de su significado. Desde el pensamiento compatible y dinámico lo que se mira es al individuo, en todas las dimensiones de su realidad personal, se afirma el papel de centralidad de la gente, de los individuos reales. Desde ese presupuesto se impulsa y promociona la identidad de cada uno, sin imposiciones ni exclusivismos. Es verdad que buena parte de la desestructuración cultural que hoy parecen sufrir las sociedades que presentan rasgos culturales más diferenciados se debe a la presión uniformadora del Estado centralista, que en demasiadas ocasiones se ha ejercido incluso con violencia. Pero no es menos cierto que esas mismas Entidades han sufrido el acoso general que en todas las partes del mundo sufren las culturas minoritarias, o incluso las culturas mayoritarias en determinados ámbitos.

Además, el compromiso con el pensamiento compatible y dinámico exige, también, una actitud de moderación y de equilibrio. Se trata de evitar las disyuntivas absolutas y traumáticas que pretenden, sean de un signo o de otro, hacer depender la propia identidad personal y colectiva de una opción política extrema, en este caso la que afecta ni más ni menos que a la soberanía. En el siglo XXI, en una España plural, solidaria y de libertades, en una perspectiva histórica que parece anunciar situaciones inéditas hasta ahora en el discurrir de la humanidad sobre el planeta, me parece que no es de la soberanía de lo que depende la pervivencia cultural y política de ningún grupo, ni de ninguna colectividad, y que el camino de futuro, en una sociedad globalizada, abierta, multicultural, sólo podrá recorrerse haciendo reales los procesos de integración que se basen en el respeto a la identidad y a la diversidad individual y colectiva. España abrió en 1978, con su Pacto Constitucional, un proceso que puede indicar el camino de semejante integración, camino que sólo podrá hacerse superando el fundamentalismo de la diferencia y el imperialismo uniformante. Europa, con otras condiciones iniciales y en otras dimensiones, ha emprendido también un difícil camino de integración, que sólo podrá ver el éxito apoyándose en estos mismos presupuestos a que hemos aludido.

Las fórmulas que conjuguen, en el juego político, de manera equilibrada, integración y peculiaridad diferencial, pueden ser muy diversas, y consecuentemente, cualquiera de ellas es aceptable. Ahora bien, la que de hecho tenemos, la que a nosotros mismos nos hemos dado, es perfectamente válida para conjugarlas, y además nos parece la más adecuada precisamente por ser la que tenemos. Cabe, es cierto, el ejercicio intelectual y dialéctico de plantearnos otras fórmulas constitucionales, y cabe también la estrategia política de formularlas. Pero unos y otra no dejan de ser juegos, en uno o en otro sentido, juegos políticos, intelectuales o verbales. Porque de hecho, lo que tenemos -y esto es ser realista- es «esta» Constitución, la de 1978, que funciona bien en términos generales. Claro que se puede cambiar el modelo territorial. Pero que se pueda cambiar no quiere decir que haya que cambiarlo. Los cambios requieren, sobre todo, de la constatación del agotamiento de los modelos. Y mientras la Constitución admita nuevos desarrollos, como los admite, los 
cambios, en mi opinión han de verificarse sobre el actual modelo territorial.

Cierto que ya resuena la cantinela de que esto es sacralizar la Constitución. No, en absoluto. La Constitución no es sagrada. Pero es el Pacto en el que se sustenta la vida y el ejercicio político de los españoles. Es el Pacto de todos, no es cualquier cosa.

De esta aproximación, Cataluña debe ser plenamente Cataluña, y no necesita debilitar su integración en España para lograrlo. El País Vasco ha de ser plenamente lo que es, no podría ser de otro modo, pero tal cosa no significa que deba producirse una «euscaldunización» obligada de quienes allí residen, antes bien debe tal proceso - si fuese pertinente - formularse como un proyecto ilusionante, abierto, y ante todo libre, sin que incorporarse a él tenga que significar necesariamente la aceptación de un criterio político único, el nacionalista. La potenciación de la propia cultura, obligada por nuestra Constitución, no puede interpretarse, ni por unos ni por otros, como un corsé que ahogue las libertades políticas. Al final la cuestión de la pluralidad de España se reconduce a la cuestión central de nuestra libertad, a que cada Comunidad Autónoma sea lo que es y como es, o la quieran hacer quienes allí viven.

Sólo desde el supuesto, repito, de la libertad y de la solidaridad es posible construir una España plural. O, expresándolo tal vez mejor, la realidad plural de España sólo puede ser aceptada y afirmada auténticamente desde el fundamento irrenunciable de la libertad y la solidaridad. Ya pasaron los tiempos de las imposiciones, del autoritarismo, a pesar de que hoy vuelvan con nuevas fauces, aparentemente tolerantes en la forma, pero férreas y contundentes en cuanto al fondo.

Es más fácil cambiar la conciencia de los hombres que cambiar la historia y la realidad. Y no es verdad que un cambio en la apreciación que tenemos de la realidad signifique de modo inmediato un cambio de la realidad misma. Sencillamente porque la realidad es terca.

La realidad es terca y es además sumamente compleja. Es más, conforme la ciencia y la tecnología parecen permitirnos una aproximación más íntima a la entraña de la realidad natural, o conforme las ciencias sociales despliegan ante nosotros, en dimensiones más completas, las actuaciones humanas, más parece justificada la convicción socrática del reconocimiento de la propia ignorancia como sabiduría propia del hombre.

El pensamiento compatible nos permitirá superar la aparente contradicción que a españolistas o defensores de un signo o de otro pretenden asentar entre la realidad de cualquier comunidad y la realidad de España. Esas realidades pueden resultar incompatibles en su conciencia, porque en los propios sentimientos, al parecer, es uno mismo quien manda, aunque a veces resulte dificultoso. Pero no son de hecho incompatibles, en absoluto, en la realidad. Es que si así fuera nada impediría la disgregación de una comuni- 
MODELO TERRITORIAL Y PRINCIPIO DE COOPERACIÓN

dad particular en virtud de procesos de afirmación municipalista o de cualquier otro tipo, o sería igualmente posible negar desde la raíz la posibilidad de un movimiento tan complejo de integración como el que representa la Unión Europea. Y con él negar las posibilidades de superación de carencias, de mejora de las condiciones de vida, de posibilidades de acciones solidarias en el mundo entero, de superación de rivalidades nacionales infructuosas y, en ocasiones, suicidas.

Estoy partiendo de la consideración de valores superiores como la convivencia, la cooperación y la solidaridad. Lo que interesa es la organización del Estado como ámbito de convivencia de todos los que ocupan los solares del territorio, a sabiendas de que la convivencia sólo es posible desde la plena aceptación de la identidad y el ser de cada quien, y no una aceptación resignada o simplemente pasiva, sino una aceptación comprometida y decidida en el fortalecimiento de cada entidad, de cualquier entidad. Ahora bien, no se puede olvidar que son también constitutivos de las Entidades lo que en ellas haya de vinculante, o de común con otras, lo que nos permitirá comprometernos definitivamente con toda entidad en un contexto integrador.

Autonomía e integración configuran un ambiente de equilibrio que debemos buscar entre todos para cada etapa histórica. Me parece que no interesa la autonomía que olvida la integración - la convivencia, la cooperación, la solidaridad - porque acaba en particularismos. Pero aún interesa menos una supuesta integración que menoscabe la legítima autonomía. Por eso el equilibrio que afirmo entre autonomía e integración no quiere decir autonomía tímida o integración moderada, sino que ambos términos se exigen mutuamente. La autonomía sin integración no es autonomía, sino disgregación; la integración sin autonomía es uniformización.

En este punto, se hace necesaria una precisión que no es baladí: no estoy usando términos -autonomía, integración- referidos tan solo a los Entes territoriales, sino al contexto más general posible, que incluye ciertamente a la concepción misma del individuo, o a cualquier institución.

Así las cosas, será fácil comprender que la cooperación al bienestar general y común, que viene a ser el mejor bien posible para cada uno, es el tipo de acción que centra nuestro interés. Pero se repara en que donde hay unidad uniforme no hay cooperación, podrá haber -todo lo más- operatividad, capacidad operativa. La cooperación implica, necesita la diversidad, la aportación plural de los que cooperan y contribuyen a la consecución de un objetivo común. El objetivo común limita en cierto sentido la capacidad de movimiento y de decisión, pero en otro la potencia y enriquece.

Ahora bien, la cooperación en ningún caso exige la pérdida de identidad. Es más, la cooperación sólo es posible desde la identidad, desde el propio genio, en el contexto plural de respeto a las posiciones ajenas. 
Este es el fecundo equilibrio que reclama la vida pública, y que sólo es posible conseguir y desarrollar con una actuación inteligente y sagaz, desde aquello que los clásicos denominaban la prudencia política.

Así pues, la actitud solidaria se traduce en la promoción de bienes, de servicios reales, palpables, a los individuos, a las personas y a las colectividades, que posibilitan su acceso a entornos más ricos de libertad y participación. Es decir, la acción solidaria no ahoga ni subordina al «beneficiario», sino que posibilita la afirmación de su identidad, que refuerza el pluralismo y la cooperación.

El vuelco que ha dado España en lo que se refiere a su articulación territorial es verdaderamente impresionante. Los que recuerden los tiempos del franquismo, en los que una uniformidad cultural monolítica pretendidamente española, que no era otra cosa que el invento de un régimen político con todas las excepciones que aquí se quieran señalar, serán quienes mejor puedan testimoniar el alcance, la profundidad de esta transformación.

Y esta experiencia, que arranca del mismo acto constituyente, ya que afecta a la misma identidad y concepción de lo que es España, es un acierto que viene avalado por la multitud de beneficios derivados de tal planteamiento. Sobre todo dos, que a mi juicio se perfilan como los fines que sintetizan los objetivos de la acción política: la libertad y la participación. El Estado autonómico, en efecto, ha facilitado y propiciado un más alto grado de participación política, habida cuenta del mayor acercamiento y proximidad de la cosa pública al ciudadano. Y mayores cotas de libertad también congruentemente con lo anterior, porque ha supuesto un refrendo político para la realidad plural española.

Esto es lo que verdaderamente interesa del proceso autonómico, lo que significa como plataforma para despertar las capacidades creativas de todos los españoles, desde su propio genio, desde su propia condición e identidad libremente asumida. Estoy convencido de que las potencialidades ocultas en esas capacidades aún no plenamente operativas, si sirve la dicción, son de un alcance difícilmente imaginable. Y no lo digo por una ensoñación complaciente, sino por la convicción que se deriva del hecho de estar en los umbrales de una nueva civilización que sólo se podrá construir sobre los supuestos económicos, informativos, relacionales, de la globalización, y sobre los culturales de la autoidentificación.

Hablar de identidad, de cultura, de autoidentificación, no es referirse a una suerte de superestructura, de adorno superfluo o de elemento extraño que no afecta a la vida productiva. Hablar de autoidentificación, de identidad es referirse a factores que son claves para el desarrollo de un mundo cada vez más globalizado y más dominado por estructuras informativas que podríamos denominar integradoras. Problemas tan importantes para el mundo del futuro inmediato como la integración social -o su contrapuesto negativo, la mar- 
MODELO TERRITORIAL Y PRINCIPIO DE COOPERACIÓN

ginación-, o la solidaridad, que no es sino un enunciado más comprensivo que el anterior, sólo podrán resolverse adecuadamente desde el respeto a la diferencia como un valor fundante de la nueva civilización, y desde la aportación diferenciada que la propia identidad permite al conjunto en que nos integramos.

El modelo autonómico se apoya en cuatro patas, por así decir: unidad, autonomía, integración y solidaridad, tal y como se deduce del artículo 2 de nuestra Constitución. En este marco el principio de cooperación, aunque no previsto expresamente, ayuda a comprender el sentido del modelo. El principio está, sin embargo, como veremos, sancionado por el Tribunal Constitucional, que ha afirmado que es de esencia del sistema. Razonamiento que deviene, también, de la lógica jurídico-política y de la experiencia de los modelos comparados.

El principio de cooperación se desenvuelve en el ámbito de las relaciones entre los distintos Entes territoriales, tanto vertical como horizontalmente, y surge de la evidencia de la necesaria complementariedad del ejercicio de las propias competencias con la concurrencia en actuaciones comunes de los diferentes poderes públicos, a partir de las cuales se tratan de obtener beneficios recíprocos, una mayor efectividad en el ejercicio de las competencias compartidas o el funcionamiento armónico de un sistema cuyos elementos son interdependientes del mismo, que no sería real y, sobre todo, no sería eficaz sin tener presente un principio, junto a los de unidad, autonomía, integración y solidaridad que se refiere al funcionamiento del sistema en su conjunto, a su aspecto dinámico: el principio de cooperación.

Curiosamente, siendo este principio un elemento presente en los modelos de Estados compuestos, no existe una formulación expresa en nuestra Constitución. Sin embargo, como ya hemos advertido, no se cuestiona desde la doctrina y desde la jurisprudencia del Tribunal Constitucional, la presencia y la necesidad de este principio en nuestra forma de Estado. Es más, el propio desarrollo del Estado autonómico y su propia práctica diaria han puesto de manifiesto, ordinariamente, la necesidad de potenciar su presencia y de articular diversas técnicas y fórmulas en el ejercicio de las respectivas competencias.

Efectivamente, la cooperación ha venido siendo objeto de mayor atención a partir de la importancia creciente que para los centros de poder iba adquiriendo la toma de conciencia de la interdependencia, determinante en muchas de las realidades sobre las que actuaban, en línea con el incremento de la intervención de los poderes públicos con el objeto de atender la mayor complejidad de las demandas sociales. La consecuencia ha sido la búsqueda de fórmulas de actuación conjuntas que pretenden el establecimiento de reglas, técnicas o modelos generales cuya finalidad es garantizar la estabilidad y la eficacia de las relaciones y de los acuerdos que surjan en las mismas. 
Partiendo del necesario respeto a la autonomía de cada una de las partes, y más en concreto al ejercicio del respectivo ámbito de competencias, la voluntariedad preside el conjunto de estas relaciones, voluntariedad que no puede entenderse como absoluta pues el resto de principios antes examinados exige una disposición de las partes a prestarse a la cooperación.

Antes bien, la cooperación surge de la necesidad de superar dos dificultades propias de los Estados descentralizados. Por un lado, la imposibilidad de establecer un diseño de distribución competencial nítido y fragmentado. Y por otro, la conveniencia de alcanzar acuerdos y llevar a cabo actuaciones que afectando a todos, persigan la complementariedad de intereses y la eficacia en su gestión.

Avanzando en el conocimiento del principio de cooperación conviene detenerse en distinguir éste de otros principios que, aunque relacionados, no pueden asimilarse al mismo, si bien en muchas ocasiones se presenten entrecruzados o se confundan entre sí. Nos referimos a los conceptos de coordinación y colaboración, conceptos que han sido abundantemente configurados y delimitados por la jurisprudencia del Tribunal Constitucional.

El primero de ellos parece previsto en nuestra Constitución como un propio título competencial en el artículo 149.1 números 13,15 y 16, referido a ámbitos materiales concretos (actividad económica, política científica y técnica, y sanidad) en los que se atribuye al Estado la competencia de coordinación. Además de título competencial concreto, la coordinación es un principio general, e implica integración de las partes en un todo realizada de forma jerárquica. Es pues una necesidad derivada de la propia estructura del Estado que aún siendo descentralizada, constituye una unidad, correspondiendo por tanto a éste la labor de coordinación.

El segundo de estos principios es el de colaboración. En este caso nos encontramos más bien ante un deber, el deber de colaborar. En este punto, el Tribunal Constitucional ha precisado que no es necesario encontrar su justificación en preceptos concretos de la Constitución, ya que se encuentra implícito en la propia esencia de la forma de organización territorial del Estado y puede considerarse análogo a conceptos como auxilio recíproco, mutua lealtad o recíproco apoyo.

El deber de colaboración no implica extensión de las competencias estatales, ni es susceptible de ser impuesto por el Estado. Consecuencia del principio de voluntariedad podría ser su consideración en el marco de las actitudes o disposiciones de cada parte integrante en sus relaciones con las demás y con el conjunto.

Hechas estas precisiones podemos avanzar que la cooperación no se configura, pues, como un deber a diferencia de la colaboración, ni como una competencia a diferencia de la coordinación: la cooperación se refiere a una 
MODELO TERRITORIAL Y PRINCIPIO DE COOPERACIÓN

forma de relación. Así, se puede hablar de las relaciones de cooperación, en el ejercicio y desde el respeto de las respectivas competencias. Sus notas características podrían plantearse en los siguientes términos.

Es un modo de articular el ejercicio de las competencias consustancial al Estado autonómico, que parte del respeto a las reglas del juego. Debe acordarse entre las instancias afectadas y su ejercicio está presidido por la voluntariedad. Por tanto, el grado de compromiso de las partes será el que ellas deseen. En fin, debe buscar métodos flexibles y adecuados de convergencia que disminuyan la conflictividad entre poderes, los cuales deben guiarse por la mutua lealtad constitucional.

El concepto de cooperación se configura, desde esta perspectiva, como un modo de ejercicio necesario o como un modo de articulación de las competencias conjuntamente con el de colaboración.

Como ya se ha señalado, la labor interpretativa del Tribunal Constitucional respecto de estos principios ha tenido una relevancia en la práctica muy significativa. Sus sentencias han venido incluyendo en numerosos casos una llamada a la cooperación que, de haber existido en la práctica, habrían evitado muchos de los conflictos suscitados.

Sin embargo, esta labor del Tribunal Constitucional no puede sustituir la capacidad de decisión política y técnica para diseñar cuáles han de ser en cada momento las fórmulas e instrumentos precisos para el buen funcionamiento del modelo. Por ello, a lo largo de estos años se ha ido desplegando un variado conjunto de técnicas y mecanismos de cooperación que si bien en un primer momento podían responder a necesidades o circunstancias puntuales, posteriormente no han sido objeto de la improvisación o de una invención desordenada, a lo que ha contribuido también la valoración de la utilidad práctica de estos conceptos.

Efectivamente, la configuración de los criterios, principios y mecanismos de cooperación se presenta a lo largo de la evolución del Estado autonómico bajo diferentes situaciones, deudoras en cada momento de la naturaleza de dicha evolución. Sin embargo, el común denominador lo hallamos en la búsqueda de soluciones a los problemas reales de los ciudadanos consecuencia de la articulación o superposición de diferentes facultades públicas en torno a la ejecución de competencias compartidas o concurrentes especialmente.

Se puede afirmar, en términos generales, que tras el proceso constituyente se abre un periodo marcado por el reparto de poder derivado de la puesta en funcionamiento de la nueva organización territorial. El proceso de traspaso de servicios acapara toda la atención, resaltando la fijación de posiciones de afirmación categórica de ámbitos propios de competencia.

El efecto de estas posiciones ha perdurado en el tiempo influyendo de manera especial sobre el desarrollo del principio de cooperación. Además, esta 
etapa vino acompañada de un incremento muy considerable de la conflictividad jurídica, fruto de las tensiones generadas en el proceso.

A la superación de esta etapa ayudó la reiterada jurisprudencia del Tribunal Constitucional, a la que ya se ha aludido, apelando a la vía de la colaboración y la cooperación; y el establecimiento de instrumentos de negociación que redujeron la conflictividad y propiciaron la resolución extrajurisdiccional de numerosos conflictos.

Además, se fue generando una conciencia sobre la necesidad de alcanzar acuerdos sobre temas concretos y de articular y desarrollar instrumentos de cooperación.

Este período coincide en el momento en que se aborda la negociación política para alcanzar un nuevo pacto autonómico, que diera respuesta a las demandas planteadas por las Comunidades Autónomas del artículo 143, y desde un primer momento se tuvo conciencia de que el establecimiento de un modelo de relaciones debía hacerse desde el acuerdo político. Además se parte del referente del federalismo cooperativo, de manera que la juridificación de la cooperación se ha producido tras una amplia experiencia de funcionamiento de sus técnicas y una aceptación voluntaria y generalizada de sus reglas.

El resultado fueron los Acuerdos Autonómicos de febrero de 1992 que incluyeron, junto con el apartado relativo a la ampliación de competencias, otro referente al desarrollo del principio de cooperación, cuyas premisas principales fueron, por un lado, recoger y potenciar las reglas o procedimientos de cooperación como formas de comportamiento político que no estuvieran en discusión, y por otro, aplazar la institucionalización y juridificación de la cooperación hasta contar con experiencia en su funcionamiento.

Con ello se pretendía un resultado práctico que no fuera rechazado por las Comunidades Autónomas. Así, una vez alcanzado el consenso político para el desarrollo del principio de cooperación, se iría extendiendo su ejercicio como reglas habituales de funcionamiento en las relaciones entre Administraciones públicas.

Transcurrida ya casi una década desde entonces, nos encontramos hoy en esa tercera etapa que hemos llamado de la institucionalización y formalización en normas jurídicas de las técnicas e instrumentos de la cooperación, a la que sin duda debe servir la experiencia acumulada en estos años, y en la que también debe buscarse el acuerdo para pactar las formas de utilización de las mismas.

Todo ello debe llevar a un desenlace en el que las relaciones de colaboración y de cooperación queden formalizadas y aseguradas no sólo como un principio o como un deber, sino como una realidad asentada sobre acuerdos, normas y usos instalados en el funcionamiento normal del Estado Autonómico. 
Y en este sentido se ha avanzado ampliamente. Hoy es habitual la existencia y utilización de numerosos instrumentos de cooperación, tanto orgánicos como funcionales, en la mayoría de los ámbitos de actuación de las Administraciones territoriales. Quizás con un comportamiento y resultados desiguales, pero que han logrado establecer una cultura compartida de la cooperación. Es por tanto el momento de lograr un soporte jurídico adecuado que permita a este principio desplegar todas sus posibilidades.

Se plantea aquí cómo y por quién se establece esta regulación. A este respecto parece pacífico que es al Estado a quien corresponde la regulación de la cooperación en el plano general, pues afectaría a todas las partes. Y para ello habrán de tenerse en cuenta algunos elementos, ya en parte aludidos.

Por un lado, la articulación de estas técnicas sólo puede efectuarse desde la autonomía de cada parte, por lo que se deberá contar con su acuerdo tanto para su regulación como para su ejercicio. Además, la distribución de competencias entre el Estado y las Comunidades Autónomas en cada ámbito material deberá ser el marco jurídico de partida de las relaciones concretas en dicho área.

Finalmente, se apunta la competencia estatal prevista en el artículo 149.1.18 de la Constitución como el título en el que se fundamente la posibilidad de dictar las bases a que se ajustarán este tipo de relaciones, es decir dentro del concepto de régimen jurídico. El propio Tribunal Constitucional ha venido a decir en alguna ocasión que estas relaciones se integran dentro del concepto de bases del régimen jurídico de las Administraciones Públicas.

De este modo, esta regulación se justificaría también como un instrumento necesario para asegurar un tratamiento común a los administrados, y además como una demanda de la propia eficacia que el artículo 103 de la Constitución exige a las distintas Administraciones Públicas.

En cuanto a la fórmula para establecer esta regulación o institucionalización, se ofrecen distintas posibilidades. Hasta ahora las normas jurídicas han venido siendo un instrumento frecuente, bien de carácter general, como la Ley de Régimen Jurídico de las Administraciones Públicas y del Procedimiento Administrativo Común, o de forma particular, en las distintas leyes sectoriales que han previsto distintos órganos de cooperación, fundamentalmente conferencias sectoriales. Pero no han sido los únicos.

Existen en la experiencia de estos años instrumentos de cooperación consolidados, como las Comisiones Bilaterales de Cooperación o algunas Conferencias Sectoriales, creadas y reguladas por actas de constitución o por propios acuerdos de estos órganos.

En cualquier caso parece llegado el momento de recoger en un cuerpo general las líneas fundamentales de todas estas técnicas, de forma que se erija 
en el referente común de las relaciones de cooperación en nuestro modelo de Estado. Referente común y compartido por todos, como premisas que lo hagan eficaz.

Concluyendo se puede afirmar que nuestro Estado autonómico requiere para su funcionamiento como tal Estado, que por todas las partes se asuma que junto al interés particular de cada una de ellas, existe un interés general más amplio por el que todas deben velar, y que esos intereses deben confluir.

Por ello, unido al concepto de cooperación está la idea de participación, idea que a su vez remite a la más amplia noción de integración política. La eficacia de esta cooperación y participación dependerá de dos factores, uno político y otro técnico: de un lado, la voluntad política de las partes implicadas; de otro, el adecuado diseño de los cauces a través de los cuales se articulen.

Años atrás, en 2003, el Gobierno de entonces comenzó un proceso destinado a la aprobación de una Ley general de cooperación. No pudo ser por circunstancias que exceden de esta intervención. Ahora, el Gobierno ha proclamado su voluntad de institucionalizar la cooperación y sus fórmulas jurídicas en un texto legal. Ojalá tenga más suerte, aunque el momento no parece propicio al entendimiento, ni siquiera para estos temas de tanta trascendencia.

Para terminar, me parece de interés comentar algunos de los temas que plantea el reciente dictamen del Consejo de Estado sobre el particular. El dictamen del Consejo de Estado de 16 de febrero de 2006, aprobado por el pleno de la institución sobre el proyecto elaborado por el Consejo, constituye, a mi juicio, una de las mejores reflexiones que un jurista puede encontrarse sobre la Constitución de 1978. Este informe es la respuesta a la consulta formulada por el Gobierno acerca de la reforma constitucional de cuatro cuestiones bien concretas: la supresión de la preferencia del varón en la sucesión al trono, la recepción en la Constitución del proceso de construcción europea, la inclusión de la denominación de las Comunidades Autónomas y, finalmente, la reforma del Senado.

A lo largo y ancho de trescientas ochenta y dos páginas, el lector puede disfrutar de un estudio bien articulado, claro y coherente en el que, además de dar cumplida respuesta a los términos estrictos de la consulta, el Consejo de Estado va más allá precisamente atendiendo a la licencia del Ejecutivo para que se pronuncie sobre otras cuestiones vinculadas a la consulta que sean convenientes para completarla o mejorar su calidad técnica. En este ámbito encontramos, a mi juicio, sabias reflexiones y comentarios que bien haría el Gobierno en secundar, precisamente porque están presididos por el sentido jurídico y la experiencia de más de veinticinco años de desarrollo autonómico.

El informe que vamos a glosar, se elabora en el marco de las nuevas funciones del Consejo según la reforma de 2004 en virtud de la cual el Órgano 
MODELO TERRITORIAL Y PRINCIPIO DE COOPERACIÓN

consultivo del Ejecutivo realizará por sí o bajo su dirección los estudios, informes y memorias que el Gobierno le solicite y elaborará las propuestas legislativas o de reforma constitucional que el Gobierno le encomiende. En el caso presente, nos hallamos ante la primera de estas nuevas funciones del Consejo en materia de reforma constitucional.

En estas líneas me propongo analizar precisamente varias cuestiones que, aunque no son propiamente objeto de la consulta, son de gran calado jurídico y político, y aparecen analizadas por el Consejo del Estado en el marco de los asuntos conectados al objeto del dictamen que pueden ayudar a mejorar técnicamente o completar la propuesta del Gobierno. A ellos, fundamentalmente, me voy a referir a continuación. Me refiero a la dimensión o naturaleza abierta del sistema de distribución de competencias, al principio de solidaridad, al principio de igualdad y al principio de colaboración o cooperación. Cuatro cuestiones que están en el frontispicio de cualquier intento de reforma constitucional en materia autonómica. Insisto, el Consejo de Estado se refiere a ellas por entender que están en directa relación con los aspectos del sistema autonómico sobre los que se plantea la reforma.

Antes de entrar en el análisis de estas cuestiones, me parece que puede ser clarificador retener algunas afirmaciones del Gobierno en el texto de la consulta. Afirmaciones que llaman la atención por su claridad y compromiso y que, en mi opinión, resultan incongruentes con el actual derrotero que está adquiriendo el proceso de reforma del Estatut. Así, tras recordar la relevancia de la Constitución de 1978, se nos dice que el «acierto en los procesos de revisión constitucional depende de la conjunción de varios factores. A saber: a) que los cambios a introducir respondan a demandas consistentes y que busquen resolver problemas o insuficiencias ampliamente reconocidas. b) que sean limitados y prudentes para no alterar el equilibrio en el que se sustenta el texto constitucional. c) que las alternativas propuestas hayan sido suficientemente maduradas y sean consecuencia de un diálogo sostenido y sereno entre las fuerzas políticas y la sociedad. d) que se genere en torno a las modificaciones un consenso asimilable al que concitó el texto que se quiere reformar» (Informe, p.7).

Desde luego, las premisas sentadas por el Gobierno están dictadas por la prudencia y el sentido del equilibrio. El problema reside en que la realidad del hoy y ahora no encaja en el ambiente más propicio para una reforma serena y acordada pues lo que observamos un día y otro también es la ausencia de diálogo entre las principales fuerzas políticas. Quizás los actores políticos debieran estar menos obsesionados por la culpa de los desencuentros y más pendientes de resolver los problemas reales de la gente pensando en cómo mejorar las condiciones integrales de vida de los ciudadanos.

En cualquier caso, no está de más certificar las buenas intenciones del Gobierno al señalar en el texto que se somete a la consulta del Consejo de Estado que «todas las propuestas que integran esta reforma de la Constitu- 
ción precisan el concurso de todos, con el objeto de alcanzar un gran acuerdo político y social que las respalde. En efecto, si bien las Constituciones para durar tienen que adaptarse a las transformaciones sociales, no debe caerse en el error de abrir sucesivos procesos de revisión constitucional, pues la norma que recoge los fundamentos de la convivencia requiere de la estabilidad necesaria para que la cultura política de la comunidad no se vea sacudida por un continuo replanteamiento de los principios y valores sobre la que descansa» (Informe, p. 11).

En este contexto, al socaire de la cuestión de la denominación de las Comunidades Autónomas, se plantea la gran cuestión del principio dispositivo, principio inspirador de todo el modelo, que ahora, en virtud de la reforma, se trata de modular. En este sentido, parece obvio que el principio dispositivo, en lo que se refiere a su inicio, a su paso de potencia a acto, al nacimiento de las Comunidades Autónomas, ha cumplido su función. Se podría decir hasta que la autonomía, que es un derecho de tracto sucesivo, que no se agota por su uso, va cumpliendo etapas. La etapa del nacimiento de los sujetos autonómicos ha terminado. Desde ese punto de vista, el principio dispositivo se debe adecuar a la realidad y, en consecuencia, sería razonable derogar los preceptos constitucionales que sirvieron en su momento para la emergencia de las Comunidades Autónomas.

En efecto, aunque ahora se trate de reflejar la realidad, el principio dispositivo plantea que el ejercicio de la autonomía, dentro de los límites constitucionales, se plasme a través de un conjunto de decisiones políticas en virtud de las cuales, por ejemplo, se pongan en marcha procedimientos de reformas estatutarias con el fin de mejorar el autogobierno. Es decir, como señala el Consejo de Estado, «el principio dispositivo no desaparece por entero, pues en cierto modo es también este principio ya transformado, el que explica que estos nuevos Entes hayan recibido su facultad de redefinir de manera indefinida el ámbito de su autonomía» (Informe, p.137). Redefinición que se articula esencialmente a través de las reformas estatutarias y que plantea el alcance y las consecuencias de la apertura del sistema, apertura que según el Consejo, no siempre origina ventajas evidentes (Informe, pp. 139-140).

Todos conocemos el proceso de instauración de las Comunidades Autónomas y su estado actual. Es posible que algunos aspectos del sistema como la diferenciación entre nacionalidades y regiones o el uso del artículo 150.2 de la Constitución hayan sido objeto de interpretaciones heterodoxas, por utilizar una expresión benévola. En realidad, hoy nos encontramos ante una situación de relativa igualdad competencial, de manera que «cualquier otra ampliación de competencias que una Comunidad pueda conseguir para sí, mediante la reforma de su Estatuto, se convierte de inmediato en objetivo obligado para todas las que todavía no han llegado a este nivel» (Informe, p. 141). Por ello, afirmar que el principio dispositivo traería consigo un mo- 
MODELO TERRITORIAL Y PRINCIPIO DE COOPERACIÓN

delo diferenciado es relativa si tenemos presente, como señala el Consejo, que «las diferencias organizativas entre todas las diversas Comunidades son pequeñas y las de los respectivos ámbitos competenciales casi todas transitorias» (p. 142).

En este contexto, la reforma estatutaria aparece como el principal instrumento para la ampliación competencial. Sin embargo, como argumenta el Consejo «cuando la reforma en cuestión sirve de hecho para formalizar acuerdos generales ya logrados, como en el caso de los Pactos autonómicos de 1992, el enfoque localista no puede dar lugar a propuestas que no vayan a ser acogidas por las Cortes Generales. Cuando, por el contrario, la propuesta de reforma surge sin acuerdo previo, en contraste entre la perspectiva particular y general, que es la propia de las Cortes Generales, ha de dilucidarse en el curso de la tramitación parlamentaria, dando lugar a una relación dialéctica entre aquéllas y los Parlamentos de las Comunidades, de la que pueden surgir tensiones perjudiciales para la vida del Estado y, a veces incluso, para la estabilidad de los partidos políticos»(pp. 142-143).

Cualquier lector avezado podrá colegir que la relación de este párrafo del dictamen con la situación del Estatut no es mera casualidad, sino que describe certeramente lo que puede ocurrir, y de hecho ocurre en estos días. De ahí que advierta el Consejo de Estado que en este contexto «los riesgos de crisis que la apertura del sistema genera se hacen más graves, por razones obvias, cuando más se acerca el ámbito competencial de las Comunidades al máximo admitido por la Constitución» (p.143). Hoy estamos, en efecto, en esta situación, en la que no es imposible, ni mucho menos, que para ampliar las competencias se acuda a interpretaciones demasiado forzadas de las normas, dando lugar a «acusaciones de que con ellas se pretenda rozar o violentar, de manera deliberada o no, los límites constitucionales. Con ello, una cuestión estrictamente jurídica se lleva al debate político, con daño tanto para el Derecho como para la política» (Ibidem). A mí, al menos, la recepción en el preámbulo de un Estatuto, vía reforma, del término nación, me parece que encaja en esta reflexión.

Así las cosas, el Consejo de Estado termina este punto afirmando que «parece razonable concluir que no carecen de fundamento las dudas que desde hace algún tiempo se manifiestan acerca de la conveniencia de mantener en vigor un principio organizativo que no produce efectos que no puedan lograrse, de manera jurídicamente más simple y políticamente menos traumática, por el simple procedimiento de llevar a la Constitución todo el sistema de delimitación de competencias» (Ibidem). Esta tesis del Consejo podría hacer pensar que se postula la práctica desaparición del principio dispositivo, el cierre hermético del modelo y la petrificación de las demandas de autogobierno de las Comunidades Autónomas. ¿Se trataría de constitucionalizar «in toto» el modelo? El Consejo de Estado, consciente del sentido de su comentario, señala a renglón seguido que su reflexión, que es la que guía el Derecho com- 
parado, no implica necesariamente una homogeneidad absoluta entre las Comunidades Autónomas y que, en cualquier caso, siempre está abierta la posibilidad de impulsar el cambio a través de la reforma constitucional. En cualquier caso, no parece posible en este momento reducir «el contenido competencial de todos los Estatutos a una simple norma que atribuyese a la Comunidad correspondiente todas las competencias que la Constitución no reserva en exclusiva al Estado, o modificar, para lograr lo mismo, el apartado 3 del artículo 149 de la Constitución» (Informe, p. 144) ni es el objeto de la reforma planteada por el Gobierno. Ni a mi me parece que, habiendo artículos como el 150.2 de la Constitución, sea la solución a las tensiones.

La propuesta del Gobierno es superar la apertura inicial del sistema, no sustituir por otro el sistema abierto que tenemos (Ibidem), lo que no impide que el Consejo haya deslizado ese comentario a pesar de que insista en que le está vedado insinuar reformas no planteadas por el Gobierno. En este sentido, la posibilidad de incluir la denominación de las Comunidades Autónomas en la Constitución, aunque presenta dificultades técnicas, lingüísticas y gramaticales es posible, de manera que en este punto el principio dispositivo quedaría modulado. En verdad, desde la misma erección jurídica de las Comunidades Autónomas este principio ya queda limitado.

El Consejo de Estado, en uso de la licencia concedida por el Gobierno, analiza, en el marco de las cuestiones estrechamente relacionadas con la reforma que podrían ser atendidas para completarla y perfeccionarla, la necesidad de una regulación más completa del principio de solidaridad, la inclusión en la Constitución del principio de colaboración o cooperación, así como la necesidad de racionalizar la apertura del sistema. En mi opinión, si los principios de solidaridad y colaboración o cooperación encontraran una adecuada regulación en la Constitución, es posible que junto a la reforma del Senado, el modelo abierto que caracteriza al sistema autonómico encontrara elementos de racionalidad que evitasen la huida hacia delante y su continua puesta en cuestión por algunos actores políticos.

Es sabido que el principio de solidaridad es uno de los principios básicos de los Estados compuestos. Es un principio jurídico, dice el Consejo de Estado, del que dimanan deberes concretos cuya observancia puede ser exigida por el Estado, por lo que parece adecuado conocer quienes son los obligados por dicho principio, qué autoridad está legitimada o habilitada para definir los deberes que de él se derivan y, eventualmente, cuáles son las consecuencias de su incumplimiento. Es verdad que la Constitución no ofrece un modelo acabado de principio. Es más, como se reconoce en el informe objeto de nuestra consideración, los preceptos de la Constitución hacen difícil determinar su ámbito y su contenido, «no sólo porque en algunas de ellas no hay alusión alguna ni a lo uno ni a lo otro, si siquiera mediante el empleo de los conceptos generales y abiertos que son propios de los enunciados constitucionales, sino también porque los obligados por la solidaridad que 
MODELO TERRITORIAL Y PRINCIPIO DE COOPERACIÓN

ocasionalmente se mencionan no siempre los mismos, ni es el mismo el deber que la solidaridad les impone» (Informe, p. 189).

En el artículo 2 de la Constitución, la solidaridad opera como principio general y se proyecta sobre las nacionalidades y regiones. En el apartado 2 del artículo 138, hay una remisión al artículo 2, pero se refiere al Estado en su acepción restringida. En opinión del Consejo de Estado, habría que superar esta discordancia «entendiendo que lo que el Estado ha de garantizar no es la solidaridad en cuanto principio sino su realización efectiva y que la tarea que la Constitución encomienda a las instituciones centrales del Estado es la de fomentar los comportamientos solidarios de las Comunidades Autónomas y combatir los que no lo sean» (Ibidem). Sin embargo, como reconoce el informe, esta interpretación, a la luz de los actuales preceptos constitucionales no es fácil de colegir.

El artículo 138, ubicado en el Título VIII, permite pensar, como entiende el Tribunal Constitucional (sentencia 150/1992), que el principio de solidaridad también opera, además de en las relaciones interautonómicas, en las intraautonómicas, haciéndose efectivo a través de un Fondo de Solidaridad Municipal. Se encomienda al Estado en virtud de este precepto «velar por el establecimiento de un equilibrio adecuado y justo entre las diversas partes del territorio español atendiendo en particular a las circunstancias del hecho insular», tarea que el Estado ha de atender en el marco de sus competencias pues este precepto no es una norma atributiva de competencia tal y como ha sentado el Tribunal Constitucional (sentencia 146/1992). El artículo 156 de la Constitución también contiene una referencia a la solidaridad entendida, junto a la coordinación con la Hacienda estatal, como principio en el marco de la autonomía financiera autonómica. Igualmente, señala el informe que no se trata de la solidaridad del artículo 2, sino de la solidaridad que existe, o debe existir, entre los españoles, cuestión que oscurece la hermenéutica del precepto y que en opinión del Consejo «parece razonable entender que los españoles concernidos por la solidaridad no pueden ser, para cada Comunidad Autónoma, sólo el conjunto de sus propios miembros, pero no es fácil discernir qué efectos puede tener la solidaridad general de todos los españoles entre sí sobre el ejercicio de las competencias financieras de las Comunidades Autónomas, puesto que la regulación de ese ejercicio ha de ser efectuada por una Ley Orgánica» (Informe, pp. 191). Finalmente, el artículo 158 de la Constitución, el que instituye el Fondo de Compensación para gastos de inversión, trata de la solidaridad como obligación del Estado para con Comunidades Autónomas y provincias.

La Constitución es parca y muy poco explícita en cuanto a la regulación de la solidaridad, lo que ha llevado, como en otras materias centrales del modelo autonómico, a que fuera el Tribunal Constitucional quien tuviera que construir el concepto. Para lo que ahora interesa, debe señalarse que de la solidaridad, como recuerda el Consejo de Estado, el Tribunal Constitucional 
ha hecho derivar él los deberes de cooperación, auxilio recíproco y lealtad (sentencias 152/1988, 236/1991 y 51/1993). Por tanto, el informe que estamos glosando señala en este punto que «parece conveniente revisar el tratamiento que la Constitución hace de este principio básico, modificando cuanto sea preciso los correspondientes preceptos» (Informe, p. 193)

A continuación, el Consejo de Estado se va a referir al principio de igualdad, tema crucial para entender el sentido del modelo y para entender el nervio del equilibrio dinámico entre unidad y autonomía en que, en mi opinión, descansa el sistema autonómico. El llamado Estado de las Autonomías implica, a partir del principio dispositivo, de la voluntariedad de los sujetos autonómicos, una razonable diferenciación en el régimen jurídico de situaciones o relaciones del mismo género $\mathrm{y}$, por ello, una cierta y relativa diversidad de derechos y obligaciones de los españoles en las distintas partes del territorio nacional (Ibidem). El problema, como es fácil de comprender, es que la diversidad del sistema, en palabras del informe «sólo es tolerable dentro de ciertos límites, más allá de los cuales se rompería la unidad del sistema»( Ibidem). Esta es la médula de la cuestión: mantener la diversidad dentro de ciertos límites que no pongan en entredicho el principio de igualdad de todos los españoles consagrado en el artículo 14 de la Constitución.

Como señala el Consejo, el principio de igualdad de los españoles ha de ser complementado con normas que sirvan tanto para garantizar la diversidad potencial como para prevenir sus posibles excesos (Ibidem). En este sentido, debemos preguntarnos por el alcance de la prohibición contenida en el artículo 138.2, según la cual las diferencias entre los Estatutos «no podrán implicar, en ningún caso, privilegios económicos o sociales». Y privilegio implica «la excepción de la regla común y, en virtud del principio dispositivo, las únicas reglas comunes a las que han de sujetarse todas las Comunidades son las establecidas en la propia Constitución, que no pueden ser exceptuadas sin incurrir en inconstitucionalidad» (Informe, p.194). En este sentido, igualdad entre Comunidades quiere decir que están sometidas a las mismas reglas jurídicas, no que puedan tener un grado de desarrollo diverso pues, como señalara el Tribunal Constitucional en la sentencia sobre la LOAPA, «el régimen autonómico se caracteriza por un equilibrio entre la homogeneidad y la diversidad del status jurídico público de las Entidades territoriales que lo integran. Sin la primera no habría unidad ni integración en el conjunto estatal; sin la segunda, no existiría verdadera pluralidad ni capacidad de autogobierno, notas que caracterizan al Estado de las Autonomías.(...). Pero como el precepto habla de privilegios económicos y sociales y no parece que quepa hablar de privilegios de esta naturaleza entre Comunidades, ha de atribuírsele un significado distinto, que no afecta a la relación de las Comunidades entre sí, sino a la de cada una de éstas con las personas físicas y jurídicas titulares de derechos y obligaciones» (Sentencia 76/1983). 
MODELO TERRITORIAL Y PRINCIPIO DE COOPERACIÓN

En este sentido, según doctrina del Tribunal Constitucional, el párrafo primero del artículo 139 no exige un tratamiento jurídico uniforme de los derechos y deberes de los ciudadanos en todo tipo de materias y en todo el territorio del Estado, lo que sería frontalmente opuesto a la autonomía, sino que se refiere a lo sumo a una igualdad de posiciones jurídicas fundamentales (sentencia 37/1987). Es decir, la igualdad se predica de las posiciones jurídicas fundamentales, concepto no especialmente claro, lo que dificulta sobremanera una interpretación del precepto congruente. Si se entiende como igualdad en el ejercicio de los derechos fundamentales, es superfluo, y si se refiere a la delimitación de lo que es fundamental en el contenido de derechos no fundamentales, es, dice el informe que estamos comentando, «una noción elusiva y difícilmente aprehensible, más propia de textos doctrinales que normativos» (Informe, p. 196).

Por tanto, la clave está en determinar si la diversidad inherente al modelo autonómico se extiende a todo género de derechos, incluidos los económicos y sociales. Es decir, si es posible, como parece, que una norma de una Comunidad otorgue a ciertos derechos un contenido más intenso o una mayor garantía que otra, entonces no haría falta tocar la Constitución. Pero si se trata de que los derechos económicos y sociales sean los mismos en todo el territorio nacional e idénticos los servicios públicos que satisfacen las correspondientes prestaciones, entonces sería necesario incorporar a la Constitución una norma en esta dirección pues se limita la autonomía de las Comunidades y se condiciona decisivamente la ordenación financiera del Estado (Informe, p. 197). Si, por el contrario, seguimos un criterio más cercano al artículo 158 de la Constitución y al artículo 15 de la LOFCA, entonces se entenderá que la función del Estado, dice el Consejo de Estado, «ha de ser la de asegurar un contenido necesario de estos derechos y un nivel mínimo de los correspondientes servicios en todo el territorio nacional, sin impedir que las Comunidades que así lo quieran vayan más allá» (Ibidem). En este caso, también la Constitución debería señalarlo inequívocamente, postula el Consejo.

El principio de solidaridad, en opinión del Consejo de Estado, debe recogerse en la Constitución de una manera más completa. El principio de igualdad en su dimensión territorial, sea cual sea la dimensión elegida, parece que también debería explicitarse en la Constitución. Es decir, se trata, en mi opinión, de que a través de la concreción de estos principios, la naturaleza abierta del sistema adquiera contornos de racionalidad. Pues bien, en lo que se refiere a los principios de colaboración y cooperación, podríamos decir otro tanto de lo mismo.

En efecto, el principio de cooperación sólo se recoge en la Constitución en el artículo 145, para referirse a la dimensión interautonómica. Nada se dice, sin embargo, de las relaciones de colaboración o cooperación entre el Estado y las Comunidades, siendo, como es un tema central de la metodología 
de las relaciones en los Estados compuestos. Por tanto, si bien la cooperación o colaboración horizontal es tratada por la Constitución, la cooperación vertical está huérfana de regulación. Por ello, y desde la convicción de que la colaboración y cooperación son principios esenciales al modelo, como ha dicho el Tribunal Constitucional, parece también atinado «reflexionar sobre la conveniencia de consagrar explícitamente en la Constitución el deber de cooperación y colaboración que pesa sobre todos los entes dotados de autonomía territorial, especialmente de las Comunidades, y de facilitar al mismo tiempo el cumplimiento de ese deber mediante una regulación más flexible de esas actuaciones concertadas» (Informe, p. 200). En otras palabras, el Consejo de Estado juzga conveniente la inclusión en la Constitución del deber de colaboración y cooperación o, si se quiere, del principio de colaboración y cooperación. Al mismo tiempo, parece aconsejarse la promulgación de una Ley de cooperación, proyecto que fracasó en la legislatura pasada y que ahora parece volver a retomarse a pesar de las reservas con que los partidos nacionalistas suelen acoger este tipo de normas.

Para terminar, es menester, al hilo de las atinadas reflexiones del Consejo de Estado, hacer algunos comentarios sobre la apertura del sistema autonómico, apertura que, si se atendieran algunas de las ideas vertidas en el informe, es probable que pudiera entenderse con un mayor grado de racionalidad y desde posiciones de mayor equilibrio entre el Estado y las Comunidades. Por supuesto que una reforma del Senado orientado a su especialización funcional en materia territorial también ayudaría a modular un sistema que requiere de más elementos de multilateralidad y de relación.

Esencialmente, la apertura del sistema autonómico encuentra su piedra de toque en la posibilidad de reformar los Estatutos, cuestión vinculada al principio dispositivo y cuyo impulso va de cuenta de la Comunidad interesada. Es verdad que los Estatutos tienen regulaciones parcialmente diferentes y que en 1993, ante las lagunas detectadas, se pensó, erróneamente, que sendas resoluciones de los Presidentes de Congreso y Senado solucionarían dichas diferencias. En fin, el panorama actual arroja, al decir del informe objeto de estudio, «un conjunto heterogéneo de normas cuyo rango formal no es adecuado a su contenido y cuya compatibilidad con la Constitución no es siempre evidente» ( Informe, p. 207). Tenemos cinco regímenes distintos para la reforma estatutaria. Esta diversidad, que en sí misma no es cuestionable, dice el Consejo de Estado, provoca cierta perplejidad. Una cosa es que los Estatutos establezcan el procedimiento que dentro de la Comunidad ha de seguir su reforma y otra muy distinta que se lleve también a ellos la regulación del procedimiento al que las Cortes Generales hayan de ajustarse en el ejercicio de sus propias potestades»( Informe, p.215). De ahí que como postula el informe, se podría reformar esta cuestión y, ya de paso, reflexionar sobre la forma que ha de adoptar la intervención de las Cortes Generales en los distintos supuestos.

El sistema abierto que diseña la Constitución tiene límites. Se puede jugar en una cancha amplia, más amplia de lo que parece. Pero en un terreno 
MODELO TERRITORIAL Y PRINCIPIO DE COOPERACIÓN

de juego acotado. Las líneas que delimitan el campo son, en este caso, las competencias exclusivas del Estado señaladas en el artículo 149 de la Constitución. Sin embargo, como sabemos, el artículo 150.2 de la Constitución permite ir más allá, aunque quizás no tanto como la realidad ha demostrado. La ampliación competencial ex artículo 150.2 es diferente a la planteada vía reformas estatutarias. Aquí estamos ante delegaciones o transferencias de ejercicio de facultades correspondientes a materias de competencia exclusiva del Estado en virtud de Leyes Orgánicas.

Es bien sabido, y está recogido en los diarios de sesiones de las Cortes, que la técnica diseñada en este precepto estaba pensada para introducir mecanismos de flexibilidad que permitieran adecuar el sistema a las nuevas circunstancias, una especie de mecanismo para mantener en el ámbito autonómico una claúsula «rebus sic stantibus». En otras palabras, aunque las Comunidades vía reformas estatutarias hubieran apurado los máximos competenciales, siempre quedará esta técnica que permitirá nuevos desarrollos, aunque sea por virtud de delegaciones o transferencias del poder nacional.

Con el fin de racionalizar nuestro sistema autonómico, el Consejo de Estado parece partidario de clarificar algunos de los excesos producidos en la praxis constitucional del artículo 150.2. En concreto, reclama que se precise que este supuesto está construido para delegaciones o transferencias, no de la titularidad de competencias, sino del ejercicio, de la gestión, si se quiere. $\mathrm{Y}$, por otra parte, que se caractericen las facultades no susceptibles de transferencia o delegación por «naturaleza»; esas que son indelegables, que forzosamente, dice el informe, habría de hacerse en términos muy flexibles y teniendo presente las que se consideren inherentes al ejercicio de la soberanía e indispensables para garantizar el correcto funcionamiento de la Administración General del Estado, así como las que no pongan en peligro la capacidad del Gobierno de la Nación para diseñar su propia política en aquellos ámbitos que la Constitución le ha reservado en exclusiva. Igualmente, ha de tenerse en cuenta para esta tarea, la competencia para definir el común denominador normativo que, en buena lógica, no puede ser cedida a una Comunidad Autónoma (Informe, p.220-221). En el mismo sentido, el informe del Consejo plantea que se precise, por lo que se refiere a las facultades susceptibles de delegación o transferencia, que lo son porque de esta manera se ejercen más eficazmente las competencias ya asumidas en sede estatutaria, con exclusión, por tanto, de todas las que se proyecten sobre materias en las que la Comunidad Autónoma no puede invocar ningún título que le habilite de una u otra forma para intervenir. La exigencia de una vinculación directa entre una o varias competencias de las que figuran en el Estatuto como propias de la Comunidad Autónoma y las que eventualmente pudieran traspasarse por el procedimiento previsto en el artículo 150.2 serviría para poner coto a la fuerza expansiva de esta técnica, sometiendo su uso a una condición que se expresa en términos positivos. Además, señala el informe, sería buena ocasión la reforma para zanjar la polémica sobre el blindaje ex Esta- 
tuto de las cesiones de competencias a través del artículo 150.2, incluyendo una expresa interdicción de la incorporación al texto estatutario de esas facultades estatales transferidas o delegadas (Informe, p.221).

En fin, se podrían abordar más cuestiones en estas líneas referidas, por ejemplo, a la reforma del Senado. Sin embargo, me parece que es momento de poner punto y final. El Consejo de Estado ha realizado una auténtica evaluación normativa de la Constitución en lo que al ámbito territorial se refiere. Ha aprovechado la licencia concedida por el Gobierno para abordar los temas más relevantes del sistema autonómico vinculados a la consulta gubernamental. En mi opinión, es necesario racionalizar el sistema incorporando el principio de cooperación en la Constitución explicitando los deberes del Estado y de las Comunidades Autónomas en relación con las reglas de juego. Es menester también precisar mejor el principio de solidaridad entre el Estado y las Comunidades Autónomas, así como el principio de igualdad en relación con la diversidad. Y, finalmente, también parece aconsejable, dado el tiempo transcurrido perfilar un poco más el artículo 150.2. Aspectos todos ellos que permiten mantener el modelo en ese equilibrio entre unidad y autonomía que ha hecho del sistema autonómico, mal que les pese a algunos, un ejemplo de descentralización en todo el mundo.

El modelo autonómico descansa sobre el acuerdo entre los partidos políticos. Así nació y así se ha desarrollado armónicamente. Ahora, por lo que parece, no se dan las condiciones para el acuerdo y la negociación por razones de todos conocidas. El tema territorial requiere de aquel ambiente que hizo posible el Acuerdo de 1978: mentalidad dialogante, atención al contexto, pensamiento abierto y plural, búsqueda continua de puntos de confluencia, capacidad de conciliar, escuchar con atención a los demás, generosidad y, sobre todo, pensar en que la política tiene mucho que ver con la mejora de las condiciones de vida de los ciudadanos. La cooperación no es sólo un principio central del modelo autonómico, sino una necesidad. 